Paideusis

\title{
Knowing as Holistic Experience: A Challenge to Plato from Jungian Sandplay
}

\section{Beatrice Donald}

Volume 17, Number 2, 2008

URI: https://id.erudit.org/iderudit/1072432ar

DOI: https://doi.org/10.7202/1072432ar

See table of contents

Publisher(s)

Canadian Philosophy of Education Society

ISSN

0838-4517 (print)

1916-0348 (digital)

Explore this journal

Cite this article

Donald, B. (2008). Knowing as Holistic Experience: A Challenge to Plato from Jungian Sandplay. Paideusis, 17(2), 75-80. https://doi.org/10.7202/1072432ar
Article abstract

Plato's suggestion that pure knowledge, described in his theory of Forms as the archetypal basis of reality, is questioned using the sequence from the key session of a Jungian Sandplay therapy case as an example of direct human experience of the archetype. As was recognized by Jung, a parallel may be drawn between Jungian archetypes and Platonic Forms in that both are primary structures contained and manifested in the phenomenal world. In Sandplay, a patient unable to transcend her quandary through reason is able to find relief from the tension of the arguing opposites within her when she creates an image with her hands, in a state of reverie, responding to an internal impetus governed not by reason alone but by spontaneous, nonverbal sensory experience. The image she creates in this way brings her into a deep relationship with herself and marks the beginning of a newly forming selfconfidence that guides her. This example illustrates the holistic nature of human experience and change processes, in therapy or in any learning context. (c) Beatrice Donald, 2008

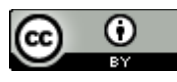

This document is protected by copyright law. Use of the services of Érudit (including reproduction) is subject to its terms and conditions, which can be viewed online.

https://apropos.erudit.org/en/users/policy-on-use/ 


\title{
Knowing as Holistic Experience: A Challenge to Plato from Jungian Sandplay
}

\author{
BEATRICE DONALD \\ Simon Fraser University, Canada
}

\begin{abstract}
Plato's suggestion that pure knowledge, described in his theory of Forms as the archetypal basis of reality, is questioned using the sequence from the key session of a Jungian Sandplay therapy case as an example of direct human experience of the archetype. As was recognized by Jung, a parallel may be drawn between Jungian archetypes and Platonic Forms in that both are primary structures contained and manifested in the phenomenal world. In Sandplay, a patient unable to transcend her quandary through reason is able to find relief from the tension of the arguing opposites within her when she creates an image with her hands, in a state of reverie, responding to an internal impetus governed not by reason alone but by spontaneous, nonverbal sensory experience. The image she creates in this way brings her into a deep relationship with berself and marks the beginning of a newly forming selfconfidence that guides her. This example illustrates the holistic nature of human experience and change processes, in therapy or in any learning context.
\end{abstract}

\section{Introduction}

From my perspective as a student of philosophy of education and having a Jungian-oriented psychotherapy background by profession, I became curious about how Plato, in his theory of Forms, exalted reason as the only conduit to true knowledge. My experience of how people meet the knowledge in the archetype disputes this claim. Although Plato and Jung would agree and disagree on the nature of the archetype, their respective positions manifest the dichotomy characteristic of philosophical discourse on the role of reason and experience in acquiring knowledge. The psychotherapy modality of Sandplay demonstrates how a mix of experience and reason is activated spontaneously by the psyche. Sandplay is a living laboratory for observing the concrete expressions of human beings working through their problems, in philosophical terminology, creating images of psychic reality that are compelled and shaped by their individual epistemological-ontological schemas. It is useful to see an example, as presented here, of how human beings in a safe, contained environment will spontaneously create a relationship with archetypal sources of knowledge to help themselves. It is useful too to think about how this human way of knowing may be applied in education, where accumulation of knowledge may create the ground for individual epistemological and ontological transformation.

(C) Copyright 2008. The author, Beatrice Donald, assigns to Paideusis the right of first publication and educational and non-profit institutions a non-exclusive license to use this document for personal use and in courses of instruction provided that the article is used in full and this copyright statement is reproduced. Any other usage is probibited without the express permission of the author. 


\section{Archetype as a Foundation for Knowing in Plato and Jung}

Plato developed his theory of Forms in the context of Greek society and a Greek world view that expressed a sustained, highly diversified tendency to interpret the world in terms of archetypal principles. ${ }^{1}$ Plato imagined his ideal Forms as the foundation of a philosophical system and political structure that would resist what he saw as the destructive influences of the individualistic, materialistic Sophists. He had a vision of the kind of state in which the individual and the state could flourish. In his ideal Republic, a chosen few capable of internalizing pure knowledge would provide benign, autocratic leadership and create a healthy society.

The inspiration for Jung's idea of the archetype, 2500 years later, came first from a dream in which he was descending the stairways of a house through rooms he described as having the décor of ever older historical epochs. Beginning with modern day surroundings, he descended the stairs and walked through rooms with sixteenth century furnishings. Further down he found himself in spaces from medieval and Roman times, and eventually at the deepest level he entered a primitive cave where skulls lay on the ground. Jung said about the dream:

It was plain to me that the house represented a kind of image of the psyche... The ground floor stood for the first level of the unconscious. The deeper I went, the more alien and the darker the scene became. In the cave, I discovered remains of a primitive culture, that is, the world of the primitive man within myself - a world which can scarcely be reached or illuminated by consciousness. The primitive psyche of man borders on the life of the animal soul, just as the caves of prehistoric times were usually inhabited by animals before men laid claim to them. ${ }^{2}$

Jung interpreted the dream as a kind of structural diagram of the human psyche. The dream became a "guiding image" of a collective psyche lying beneath the personal psyche ${ }^{3}$ and marked the beginnings of Jung's formulation of the collective unconscious and its contents, the archetypes. Jung continued developing his understanding of archetypes from his observations and analysis of the universal patterns of psychological expression in his and his patients' dreams and fantasies, his encounters with aboriginal cultures where he observed universal psychic phenomena in ritualistic, spiritual and religious practices, and his wide reading and investigations of mythology, religion, philosophy and mysticism. ${ }^{4}$

Although their life work, objectives, and the socio-cultural context in which they lived differed greatly, Plato and Jung held in common a theory of the significance and role of the archetype in human knowledge and life. Both understood archetypes to be a priori underlying structures or forms that were for Plato the essences of reality, and for Jung, innate instinctual psychological patterns of developmental and behavioural potentialities shared by humankind. Plato applied a hierarchical vision of the archetype or Idea, considering it far superior to the everyday, concrete world of transient things, and perceiving it as accessible only to philosophers through rigorous, mathematical training and discipline. For Plato, the archetype was the absolute, immovable truth in Beauty, Justice and the Good, against which the virtue in external realities could be measured. Plato did not trust the vagaries of subjective sensory experience, which were subject to human whim. The archetypal Forms, however, were impervious and fundamental. Jungian archetypes reside in the psyche of every human being as psychic structures, that is, they are not visible, except in how the individual expresses them. Jung rejected the tabula rasa theory of human psychological development, ${ }^{5}$ instead claiming that we are born

\footnotetext{
${ }^{1}$ Richard Tarnas, The Passion of the Western Mind (New York: Ballantine, 1991), 3.

${ }^{2}$ C.G. Jung, Memories, Dreams, Reflections (New York: Vintage, 1989), 160.

${ }^{3}$ Ibid.

${ }^{4}$ S. Segaller and M. Berger, The Wisdom of the Dream (Boston: Shambhala, 1990), 4.

5 Anthony Stevens, Archetype Revisited (Toronto: Inner City Books, 2003), 121.
} 
with innate predispositions for psychic functioning which are activated throughout life by our experiences with others and the culture in which we live. Developmental processes, such as being mothered, establishing a place in the social hierarchy, marrying, and so on, are examples. In the words of Jungian analyst and psychiatrist Anthony Stevens: ${ }^{6}$

In Jung's view, as opposed to Plato's, the mental events we experience are determined not only by our personal history, but by the collective history of the species as a whole (biologically encoded in the collective unconscious), reaching back into the primordial mists of evolutionary time.

In both Plato's and Jung's writing, ${ }^{7}$ we come across ambiguities as to the meaning of archetype or the Form, but for the purposes of this essay, the descriptions above are taken as central.

The archetypal hypothesis has been revisited since Platoby others with a similar point of view to Jung's. For example, linguists Noam Chomsky and Steven Pinker, who reject assumptions that language is acquired through imitation and learning and reinforced by rewards and punishments. ${ }^{8}$ In Chomsky's view, every child comes into the world fully equipped with "deep structures" in the brain, which hold the potential to acquire language. This view parallels that of affective neuroscientist Jaak Panksepp who has analyzed core structures of emotion in humans and animals and found that all organisms come into the world with a variety of abilities that do not require previous learning, but which provide immediate opportunities for learning to occur. ${ }^{9}$ More evidence for Jung's approach is accumulating from studies by evolutionary psychologists and psychiatrists Charles Card, Richard Gray, George Hogenson and Meredith Sabini, for example, who continue to dig deeper into the nature of human archetypal structures they call "mentalities," "master programs," "propensity states," "genetically transmitted response strategies," "evolved psychological mechanisms," "prepared tendencies," or "multiple mental modules." 10

\section{An Experience of the Archetype in Sandplay}

In the expressive therapy modality of Sandplay, the patient works self-directed, in a sandtray of specific dimensions ( $28 \frac{1}{2} \times 19^{1 / 2} \times 3$ inches) that is contained within the line of vision. The patient works and shapes the sand using her sensory-rich hands. ${ }^{11}$ The patient may also choose to place in the sand figurines from a "universe in miniature" displayed on shelves. As she creates a world, her world, her mind is occupied in an effortless state of reverie or fantasy-thinking directed by her unconscious and imagination. During and/or following the completion of a creation, the patient makes meaning of her experience with verbal narrative. In the example presented below, the patient's instinctive combining of sensory perception with reason, unconscious knowing with conscious awareness, mind and body, spirit and matter, underlines the holistic human experience embedded in the transformative process of "coming to be."

6 Ibid., 45.

7 These are reviewed in Richard Tarnas The Passion of the Western Mind (New York: Ballentine, 1991), 11-12; and in Anthony Stevens, Archetype Revisited, 84-85.

8 Stevens, Archetype, 48.

9 Jaak Panksepp, Affective Neuroscience: The Foundations of Human and Animal Emotions (New York: Oxford University Press, 2005), 25-28.

10 Stevens, Archetype, 53-54.

11 The hands occupy a significant area of somatosensory territory in the sensory cortex, as illustrated in the diagram of the sensory homunculus, which depicts the location and amount of cortical space devoted to processing tactile signals from different places on the body. See J.M. Swartz, M.D., The Mind and the Brain: Neuroplasticity and the Power of Mental Force (New York: Random House, 2002), 170-171. 
The creation by a young woman of the Sandplay image below (see Figure 1: Sandplay photograph) illustrates the interplay of sensory experience and reason that recalls the process of knowing described by Eugene Gendlin, who emphasizes in his "Philosophy of the Implicit," the relationship between thinking and felt meaning in acquiring knowledge. Gendlin proposes experiential concepts as bridges between phenomenology and logical formulation and places a high value on subjective experience as it informs logic, and vice versa. ${ }^{12}$

The initial process of accessing the archetypes in this image occurred through reverie and sensing, and the logic of meaning-making. The patient allowed herself to be at play, as she responded to her sense experience of what was important to her from among the hundreds of objects or miniatures available to her.

The patient was in turmoil about her relationship with her partner, a man who was susceptible to a drug addiction he attempted to hide and deny. The patient's mother had also been addicted and as a young daughter, the patient had been her mother's and her disabled brother's caretaker, a role she was falling into once again, with her partner. This young woman's struggle to understand and to resolve the opposites arguing inside her was unrelenting and intellectually unresolvable, but when she also consulted her implicit knowing in the "felt meaning" she experienced as she approached the figures she chose, she could begin absorbing the knowledge she was seeking.

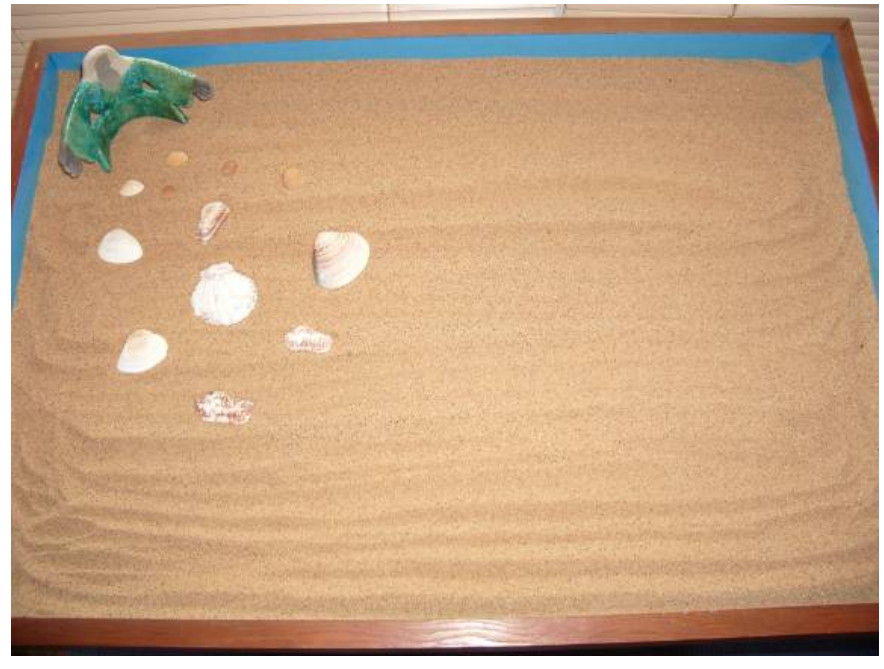

Figure 1: Sandplay photograph

The photograph was created spontaneously, without any direction from the therapist. As described above, the image is a creative concretization of experiencing in the moment and consists of universal and personal elements that interact with one another to form a whole. The picture mediates unconscious and conscious experiences represented by the objects in themselves, how and where they are placed in the sand, their interrelationships and physical relationship to the patient, and accompanying narrative. This client said, without prompting of any kind,

This is Mother Earth (the green figure in the far left corner) and these are all the shells coming out of her body on the beach...like she's giving birth. On some level maybe we all come from the ocean. [Then, touching the shells, she continued,] "Remembering that my body is capable."

\footnotetext{
${ }^{12}$ Eugene Gendlin, Experiencing and the Creation of Meaning (Evanston: Northwestern University Press, 1997) and Eugene Gendlin, Focusing-Oriented Psychotherapy (New York: Guilford, 1996).
} 
The picture is rich with imagery that contains archetypal themes common to all human beings. For example, all members of the human race in all cultures have experienced being born, though few would remember it. But birth and rebirth are also transformative psychological processes. People describe feeling reborn when they have broken through a psychological barrier, freed themselves of a perception, feeling or belief that is in some way restricting, or have had an exceptionally fulfilling experience. The context of the image is the ocean and, as the source of life (which the patient herself speaks of), is associated with the mother and the unconscious psyche. As noted by Anthony Stevens, ${ }^{13}$ the association between sea and mother archetype is apparent not only in dreams but also in many languages: mère, mer (Fr.); madre, mare (It.). This association stresses the life-generating potential of the unconscious. Shells are also associated with the waters in which they are formed and share the fertility and feminine symbolism which belongs to water. ${ }^{14}$ In the Stone Age, sea shells used as funeral ornaments were believed to give that person new life and presupposed birth, death and rebirth on the pattern of the phases of the Moon 15

This picture is a projection of an individual patient's psyche, yet it expresses at the same time, without directed thought to guide her, the bigger, archetypal humanity within her. This knowledge was accessed within a process of inter-being between direct experience and cognitive reflection in her narrative.

When an individual has received inadequate mothering-where the personal mother has been unable to offer "good enough" mothering, ${ }^{16}$ that is, the contingent communication, mirroring, safety and freedom a child needs in order to "feel felt"- there is often an expression in Sandplay of a strong connection to the Great Mother archetype, which is sometimes symbolized by strong (full, prominent) representations of nature. The archetypal potential in the child points to the natural world as a more sufficient container for the longing to be psychically and physically held. This particular client chose these figures; another individual would perhaps choose different figures which have also throughout human history been associated with the feminine and rebirth. The archetypal impetus may be expressed through different symbols. This picture is a metaphor for the patient's discovering within herself the power to change her old patterns of behaviour, to become accepting and valuing of herself. It expresses her readiness to move toward something new and differentiated from the old patterns of childhood. In her life, this is what she is realizing and actualizing.

\section{Conclusion}

Sandplay is presented here to demonstrate the organic, holistic process involved in transformative learning. In this case, the learning is about changing perceptions and beliefs about self and others, and about changing practiced behaviour. I suggest that in traditional learning settings, where the focus of learning is external (though here too learning about oneself is often an outcome), the human learning process is comparable, if not the same. The example of the Platonic and Jungian understanding of the archetype as source of knowledge, and the juxtaposition of Plato's emphasis on reason as the sole pathway to knowledge against the embodied process that precipitates change in Sandplay, both show why in contexts of learning, growth and development, a combination of intellectual and experiential

\footnotetext{
13 Anthony Stevens, Ariadne's Clue: A Guide to the Symbols of Humankind (Princeton: Princeton University Press, 1999)113.

${ }^{14} \mathrm{~J}$. Chevalier \& A. Gheerbrant, A Dictionary of Symbols (Cambridge: Blackwell, 1994), 871-872.

${ }^{15}$ Ibid.

${ }^{16}$ D.W. Winnicott, Playing and Reality (New York: Penguin, 1971), 11-12. Winnicott was a British child psychiatrist who described the "good enough" mother (not necessarily the child's own mother) as one who actively adapts to the child's needs, an active adaptation that gradually lessens, according to the child's growing ability to tolerate her failures and to tolerate the results of frustration.
} 
dimensions is important, and why we need to attend to the temptation to assign greater importance to reason over lived experience.

\section{References}

Birkhauser-Oeri, S. The Mother. Toronto: Inner City Books, 1988.

Chevalier, J. \& Gheerbrant, A. A Dictionary of Symbols. Cambridge: Blackwell, 1994.

Eliade, M. Images and Symbols: Studies in Religious Symbolism . Princeton: Princeton University Press, 1991.

Gendlin, Eugene T. Focusing-Oriented Psychotherapy. New York: Guilford, 1996.

Gendlin, Eugene T. Experiencing and the Creation of Meaning: A Philosophical and Psychological Approach. Evanston: Northwestern University Press, 1997.

Jung, C.G. Memories, Dreams, Reflections. New York: Random House, 1963.

Panksepp, Jaak. Affective Neuroscience: The Foundations of Human and Animal Emotions. New York: Oxford University Press, 2005.

Robinson, D., and Groves, J. Introducing Plato. Toronto: Penguin, 2005.

Segaller, S., and Berger, M. The Wisdom of the Dream. Boston: Shambhala, 1990.

Solomon, R., and Higgins, K. A Passion for Wisdom. New York: Oxford University Press, 1998.

Stevens, A. The Two Million-Year-Old Self. New York: Fromm International Publishing, 1997.

Stevens, A. Ariadne's Clue: A Guide to the Symbols of Humankind. Princeton: Princeton University Press, 1999.

Stevens, A. Archetype Revisited. Toronto: Inner City Books, 2003.

Schwartz, Jeffrey M. \& Begley, S. The Mind and the Brain: Neuroplasticity and the Power of Mental Force. New York: HarperCollins, 2002.

Winnicott, D.W. Playing and Reality. New York: Penguin, 1971.

\section{About the Author}

Beatrice Donald is a Ph.D. student in Philosophy of Education at Simon Fraser University. She is a psychotherapist and supervisor in individual and family therapy, and a certified teacher and supervisor in Sandplay therapy, founded in Switzerland by Jungian analyst Dora Kalff. She has published articles on Sandplay in Japanese, American, German and Lithuanian journals, and has taught and presented on Sandplay in Canada, Switzerland, the United States and Korea. She can be reached at beadonald@shaw.ca. 